\title{
ECCLESIASTICAL CONNECTIONS OF MEDIEVAL MATARCHA: NEW FINDS OF BYZANTINE LEAD SEALS
}

\author{
Viktor N. Chkhaidze \\ Institute of Oriental Studies of the Russian Academy of Sciences, Moscow, Russian Federation
}

\begin{abstract}
Introduction. Matarcha was the cathedral city of the Diocese of Zichia of the Patriarchate of Constantinople. It was a major religious and missionary center in the Northwestern Pre-Caucasus. The priests of this autocephalous archdiocese took an active part in the church life of the Byzantine Empire. In this context, among the most important sources on the history of the Byzantine Matarcha, a special place is occupied by the monuments of Byzantine sphragistics. Methods. The paper examines three Byzantine church seals of the $11^{\text {th }}-12^{\text {th }}$ centuries, discovered during the research of the Taman settlement (medieval Matarcha was the center of the diocese of Zichia of the Patriarchate of Constantinople). The owners of the seals were: deacon Michael, monk Ignatius and nun Euphemia. Analysis. The article provides information about the previously known 19 seals belonging to the church hierarchs of Zichia and other representatives of the clergy. Similar finds of seals in the Crimean urban centers (Cherson and Sughdea) are indicated. Results. The few details that relate to the ecclesiastical history of the diocese of Zichia emphasize the exceptional value of each new find of seals, and the evidence of direct contacts and established correspondence between the Orthodox clergy once again shows that, in addition to the cleric - deacon, the monastic brotherhood also played a significant role in the development of relations between the church and society. To a certain extent, this could also be facilitated by the trips of the city's residents to pilgrimage sites, as evidenced by the brought relics, the finds of which are known.
\end{abstract} relations.

Key words: history of Byzantium, sphragistics, Byzantine seals, Patriarchate of Constantinople, inter-church

Citation. Chkhaidze V.N. Ecclesiastical Connections of Medieval Matarcha: New Finds of Byzantine Lead Seals. Vestnik Volgogradskogo gosudarstvennogo universiteta. Seriya 4. Istoriya. Regionovedenie. Mezhdunarodnye otnosheniya [Science Journal of Volgograd State University. History. Area Studies. International Relations], 2021, vol. 26, no. 6, pp. 112-118. (in Russian). DOI: https://doi.org/10.15688/jvolsu4.2021.6.9

УДК 902(653):929.651

Дата поступления статьи: 03.06.2021

ББК 63.444-428

Дата принятия статьи: 14.09.2021

\section{ЦЕРКОВНЫЕ СВЯЗИ СРЕДНЕВЕКОВОЙ МАТАРХИ: НОВЫЕ НАХОДКИ ВИЗАНТИЙСКИХ ПЕЧАТЕЙ}

\author{
Виктор Николаевич Чхаидзе \\ Институт востоковедения РАН, г. Москва, Российская Федерация
}

\begin{abstract}
Аннотация. В работе рассматриваются три византийские церковные печати XI-XII вв., обнаруженные при исследованиях Таманского городища (средневековая Матарха - центр епархии Зихии Константинопольского патриархата). Владельцами печатей являлись: диакон Михаил, монах Игнатий и монахиня Евфимия. Приводятся сведения об известных ранее 19 печатях, принадлежащих церковным иерархам Зихии и иным представителям клира. Указывается на аналогичные находки печатей в крымских городских центрах $\widetilde{\widetilde{\delta}}$ (Херсон, Сугдея). Немногочисленность сведений, касающихся церковной истории Зихской епархии, осо근 бенно подчеркивает исключительную ценность каждой новой печати, а свидетельства прямых контактов и налаженной корреспонденции между православным духовенством лишний раз показывают, что, помимо ๆ клирика - диакона, заметную роль в развитии взаимоотношений между церковью и обществом играла и монашествующая братия.

Ключевые слова: история Византии, сфрагистика, византийские печати, константинопольский патриархат, межцерковные связи.
\end{abstract}


Цитирование. Чхаидзе В. Н. Церковные связи средневековой Матархи: новые находки византийских печатей // Вестник Волгоградского государственного университета. Серия 4, История. Регионоведение. Международные отношения. - 2021. - Т. 26, № 6. - C. 112-118. - DOI: https://doi.org/10.15688/jvolsu4.2021.6.9

Введение. Матарха - кафедральный город епархии Зихии Константинопольского патриархата, являлась крупным религиозным и миссионерским центром в Северо-Западном Предкавказье. Предстоятели этой автокефальной архиепископии принимали активное участие в церковной жизни Византийского государства [11]. В этом контексте в ряду важнейших источников по истории византийской Матархи X-XII вв. особое место занимают памятники византийской сфрагистики. Именно благодаря введению в научный оборот новых моливдовулов становятся известными сведения, недоступные по другим источникам. Помимо административной и частной корреспонденции, сфрагистические находки освещают и переписку представителей клира этой архиепископии, немногочисленные моливдовулы которых показывают связи не только с патриаршим престолом, центральными церковными управлениями, но и с провинциальными епархиями.

Методы. Памятники сфрагистики, как объекты церковной археологии, позволяют раскрыть новые данные по средневековой истории Северо-Восточного Причерноморья. К настоящему времени обнаружено 19 моливдовулов X-XII вв., принадлежащих отцам церкви.

Нам известны печати собственно иерархов Зихии: архиепископа Антония (40-50-е гг. XI в.) - шесть параллельных экземпляров [8, с. 95-98, № 54.1-5; 11], а также не названного по имени проэдра (архиепископа) (XI в.) - четыре параллельных экземпляра [8, c. 98-99, № 55.1-2; 17, p. 166-167, no. 1825 ; 18, p. 194-195, no. 87.1].

Новые данные сфрагистики позволили осветить контакты епархии с функционерами других провинциальных кафедр из разных регионов империи - близлежащего крымского и трех малоазийских: Иоанна, епископа Готии (X-XI вв.) [8, с. 94-95, № 52; 9, с. 169-171, рис. 2], Иоанна (?), митрополита Айноса (Фракия) (XI в.) [8, с. 92-93, № 51], Никифора, митрополита Иераполя (Фригия Пактиана или Манбидж) (2-я четверть - конец XI в.) [8, с. 94, № 53], Иоанна, митрополита
Трапезунда и синкелла (середина ХІ в.) [12, с. 291-292, рис. 1]. Подобную ситуацию в $\mathrm{X}-\mathrm{XII}$ вв. можно наблюдать в Херсонесе, где встречены печати архиепископов Боспора, Сугдеи, Анхиала (Болгария) и без указания центра $[1$, с. $132-134 ; 2$, с. 26-27, рис. $2-3 ; 3$, с. 353 , рис. $1 ; 6$, с. 94 , рис. 3].

О непосредственной связи архиепископии Зихии с Константинополем свидетельствует, к примеру, печать Георгия, монаха, кувуклисия и экзарха (Х в.) [8, с. 99-100, № 56], который мог представлять в Матархе константинопольского патриарха. Крайне редкой в Северном Причерноморье ${ }^{1}$ является находка печати столичного монастыря - в данном случае Христа

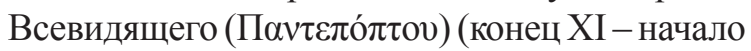
XII в.) $[8$, с. 103-104, № 60].

Наконец, следует указать на моливдовулы представителей духовенства: Константина, пресвитера, императорского клирика (XI в.) [8, с. 102, № 59], Василия, диакона и хартулария (ХІ в.) [8, с. 100-101, № 57; 13, с. 424-425, рис. 2]. Отметим также найденную в Херсонесе печать клирика Льва Тсапарина (XI в.) [14, p. 150 , no. 13].

Отдельно отметим печать Афанасия, монаха (2-я половина XI в.) [8, с. 101, № 58; 13, с. 423-424, рис. 1]. Печати XI-XII вв., принадлежащие монахам, известны в Сугдее (Николай и Феодул) [7, с. 88-89, № 13, табл. LXI, 13; 19, p. 128-129, no. 11] и Херсонесе (Каллиник) [4, с. 20, рис. 1].

Анализ. В настоящее время к перечню корреспондентов, осуществлявших традиционные межцерковные контакты, можно добавить троих представителей церкви, чьи печати были обнаружены в 2015 г. в море под Таманским городищем. В настоящее время моливдовулы находятся на хранении в Таманском археологическом музее.

1. Печать Михаила, диакона (XIXII вв.) (рис. 1).

Печать плохой сохранности, значительно затерта. Диаметр - 15-13 мм, толщина 1,5 мм, вес $-1,93$ г.

Аверс: нечеткая фигура Архангела Михаила погрудно. Титла по обеим сторонам не 


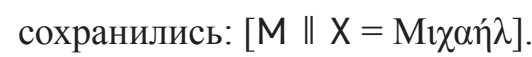

Реверс: надпись в пять строк: .СФР. | $. I C M I X A|. \Lambda \in V T \in| . O V C \Delta .|\ldots N O .=[\dagger] \Sigma \varphi \rho[\alpha-]|$

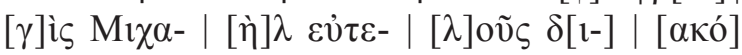
vo[v].

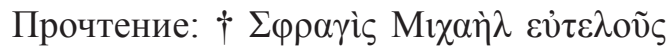
$\delta$ เoкóvov-«† Печать Михаила, худого диакона».

Надпись на печати додекасиллабическая. Известны три параллельных экземпляра, исполненные одной парой матриц - из Афинского музея $[15$, S. 168 , no. 1898; 21, б. 71, № 247; 16, p. 18, no. 1044; 20, S. 571, no. 2595a], coбpaния Fogg Museum of Art (BZS.1951.31.5.812) и Dumbarton Oaks (BZS.1958.106.379).

Еще на двух моливдовулах XI в. - из Американского Нумизматического общества (Нью-Йорк) [16, р. 18 , по. 1045; 20 , S. 571, no. 2595b] и собрания Dumbarton Oaks (BZS.1955.1.5013) - присутствует аналогичная легенда, однако представленная в четырех строках. На аверсе также изображен погрудно Архангел Михаил.

Следует указать и на печать XI в. из собрания Fogg Museum of Art (BZS.1951.31.5.450): эта же легенда в четыре строки, но на лицевой стороне изображен латинский крест на двух ступенях [20, S. 571, no. 2595c].

2. Печать Игнатия, монаха (XI в.) (рис. 2)

Диаметр - 22-20 мм, толщина - 1,5 мм, вес $-4,18$ г. Греческая легенда представлена с обеих сторон - подобный тип широко известен в XI веке.

Аверс: трехстрочная надпись, заключенная в ободок: +CФРА | ГІСІГNA | TIOV = $\dagger \Sigma \varphi \rho \alpha-\left|\gamma i \varsigma^{\prime} I \gamma v \alpha-\right|$ tíov.

Реверс: трехстрочная надпись, заключенная в ободок: $\in U T \in|\wedge \forall C M O N O|$ TPOП૪ =

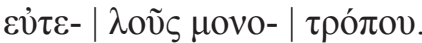

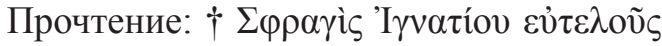

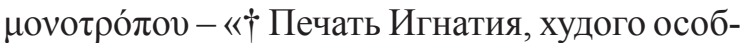
ножителя» (то есть монаха).

Надпись на печати додекасиллабическая, в издании «Corpus der byzantinischen Siegel mit metrischen Legenden» отсутствует. Аналогии печати неизвестны.

3. Печать Евфимии, монахини (XIXII вв.) (рис. 3).

Диаметр - 15-13 мм, толщина - 2,5 мм, вес $-3,84$ г.

Аверс: в ободке - Богородица Оранта в нимбе, погрудно, перед нею - изображение младенца Христа в медальоне. По сторонам от фигуры Богородицы титла: . . $\| \theta=[\mathrm{M}(\eta \tau \eta े \rho)] \Theta(\varepsilon о \tilde{)})$.

Реверс: оттиск смещен влево. Надпись в пять строк, заключенная в ободок: .ӨКЄ | . $\mathrm{OH} \Theta \ldots \mathrm{H}|. \mathrm{H} \triangle \forall \in U|$. HMIA | .ONAXH =

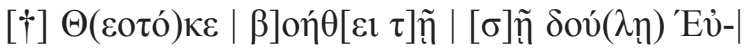
$[\varphi] \eta \mu i ́ \alpha \mid[\mu]$ ov $\alpha \chi \tilde{n}$.

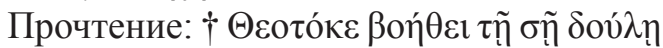

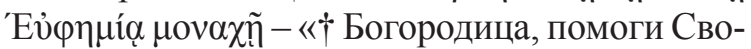
ей рабе Евфимии, монахине».

Аналогии печати неизвестны.

Два моливдовула XII в., близкие рассматриваемому по композиции (на аверсе -

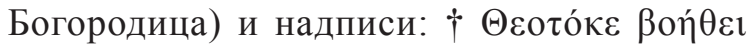

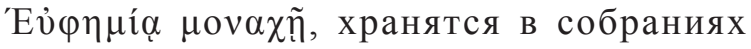
Dumbarton Oaks (BZS.1958.106.384) [17, p. 278, no. 2007, pl. 49, 2007] и Fogg Museum of Art (BZS.1951.31.5.3653) [16, p. 296, no. 1466, pl. 180, 1466].

Результаты. Таким образом, представленные свидетельства о прямых контактах и налаженной корреспонденции между православным духовенством показывают, что, помимо клирика - диакона, заметную роль в развитии взаимоотношений между церковью и обществом играла и монашествующая братия. Этому в известной мере также могли способствовать не только контакты клириков и монахов, но и путешествия жителей города по паломническим местам, свидетельством чему являются привозимые реликвии (см.: [10, с. 267-269, рис. 1]).

Немногочисленность сведений, касающихся церковной истории Зихской епархии, особенно подчеркивает исключительную ценность каждой новой печати, поскольку это позволяет ввести в оборот дополнительную информацию в более широком контексте - касающемся в целом всего северо-причерноморского региона.

\section{ПРИМЕЧАНИЕ}

${ }^{1}$ О связях таких клерикальных институтов, как византийские монастыри, с еще одним церковным центром, находящимся на окраине греческой ойкумены, на границе северных владений византийской державы - Херсоном, также свидетельствуют находки в нем моливдовулов монашеских обителей XI-XII вв. [5, с. 228-234, рис. 2-4]. 
B.Н. Чхаидзе. Церковные связи средневековой Матархи: новые находки византийских печатей

\section{ПРИЛОЖЕНИЕ}
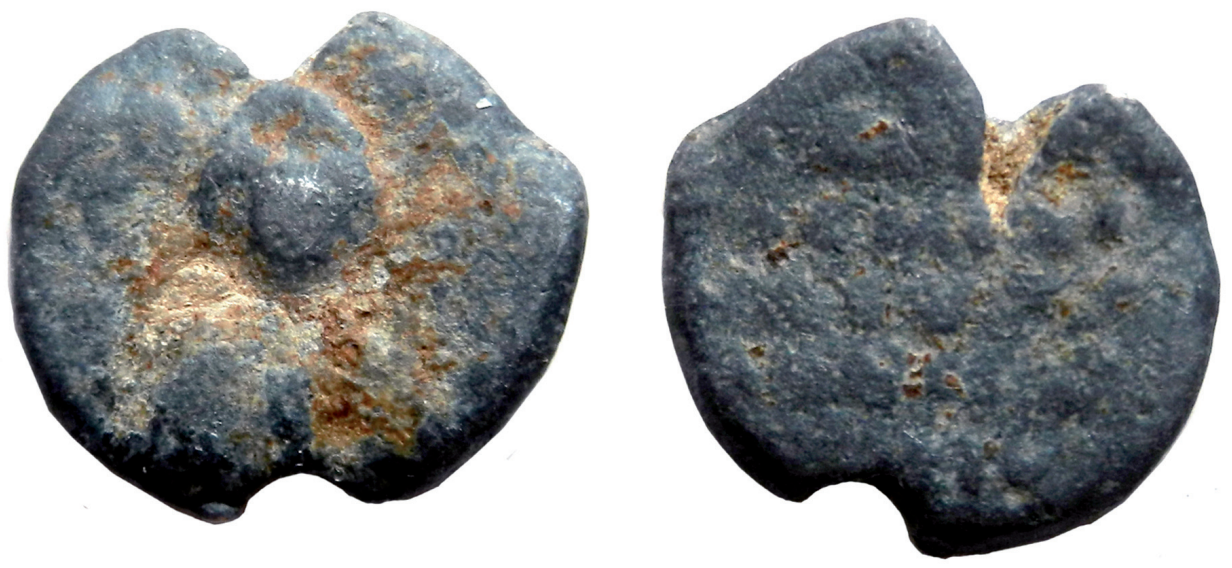

Рис. 1. Печать Михаила, диакона (XI-XII вв.)

Fig. 1. Seal of Michael, deacon $\left(11^{\text {th }}-12^{\text {th }}\right.$ centuries $)$
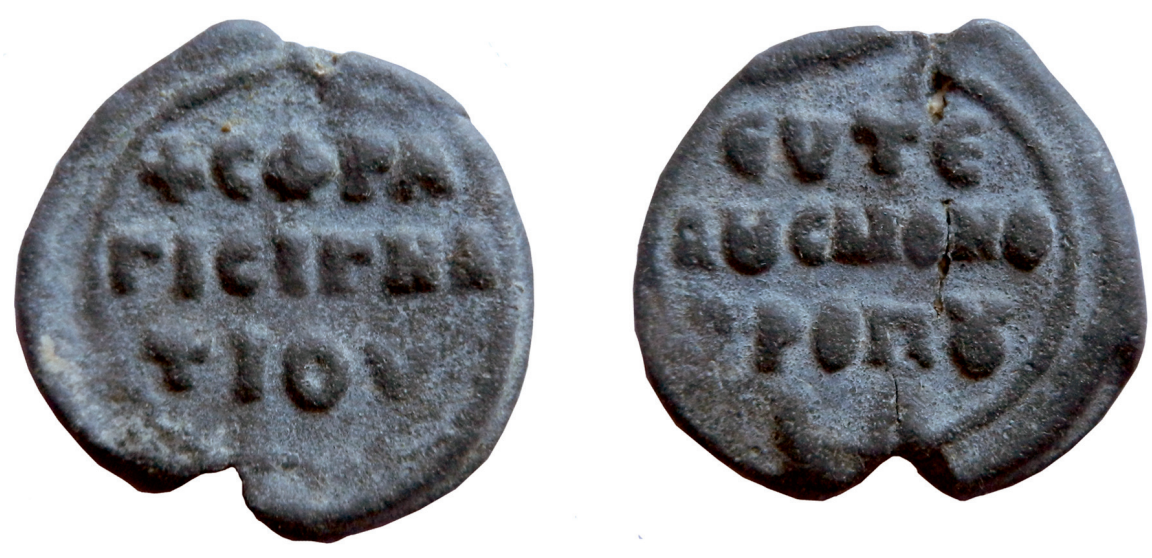

Рис. 2. Печать Игнатия, монаха (XI в.)

Fig. 2. Seal of Ignatios, monk ( $11^{\text {th }}$ century)
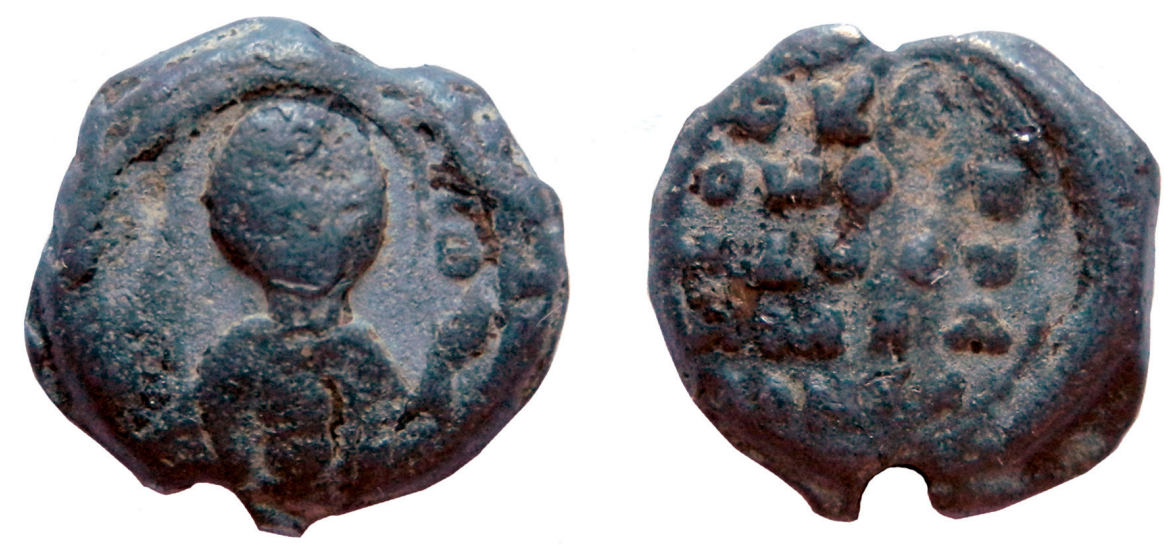

Рис. 3. Печать Евфимии, монахини (XI-XII вв.)

Fig. 3. Seal of Euphemia, nun $\left(11^{\text {th }}-12^{\text {th }}\right.$ centuries $)$ 


\section{СПИСОК ЛИТЕРАТУРЫ}

1. Алексеенко, Н. А. Моливдовулы боспорских епископов из Херсона / Н. А. Алексеенко // Проблемы религий стран черноморскосредиземноморского региона. Т. II. - Севастополь ; Краков : Национальный заповедник «Херсонес Таврический», 2001. - С. 131-138.

2. Алексеенко, Н. А. Церковная сфрагистика : Sacrum et Profanum Константинопольского патриархата / Н. А. Алексеенко // Sacrum et Profanum. Вып. IV : Религия в жизни человека и общества. Севастополь : Национальный заповедник «Херсонес Таврический», 2009. - С. 25-29.

3. Алексеенко, Н. А. Памятники археологии в ряду источников по популяризации и развитию современного туризма : Несколько новых моливдовулов болгарского происхождения / Н. А. Алексеенко // Оттука започва България. Материали от втората национална конференция по история, археология и культурен туризъм «Пьтуване към България». - Шумен : Университетско издателство «Епископ Константин Преславски», 2011. С. 352-359.

4. Алексеенко, Н. А. «Тебя, хранителя моей души и моих писаний, вырезываю на моей печати...» / Н. А. Алексеенко // Вестник Волгоградского государственного университета. Серия 4, История. Регионоведение. Международные отношения. 2015. - № 3 (33). - C. 19-29. - DOI: http://dx.doi. org/10.15688/jvolsu4.2015.3.2.

5. Алексеенко, Н. А. Межцерковные связи византийской Таврики: традиции и новации (находки византийских моливдовулов в Херсоне и его округе) / Н. А. Алексеенко // Боспорские исследования. - 2019. - Вып. XXXVIII. - С. 225-241.

6. Алексеенко, Н. А. Моливдовулы деятелей церкви из херсонского архива : Новые находки / Н. А. Алексеенко, Ю. Н. Самойленко // Нумизматични, сфрагистични и епиграфски приноси към историята на Черноморското крайбережие. - Варна : Книгоиздателство ЗОГРАФ, 2008. - С. 91-99. (Acta Musei Variaensis ; VII-2).

7. Лихачев, Н. П. Моливдовулы греческого Востока / Н. П. Лихачев. - М. : Наука, 1991. 359 с. - (Научное наследство ; т. 19).

8. Чхаидзе, В. Н. Византийские печати из Тамани / В. Н. Чхаидзе. - М. : Ин-т археологии PAH, 2015. - 202 c.

9. Чхаидзе, В. Н. Печати Иоанна, архиепископа Готии (X-XI вв.) / В. Н. Чхаидзе // Российская археология. - 2016. - № 2. - С. 169-174.

10. Чхаидзе, В. Н. Паломническая ампулаевлогия с Таманского городища / В. Н. Чхаидзе // Мир Православия. Вып. 10. - Волгоград : Изд-во ВолГУ, 2019. - С. 266-271.
11. Чхаидзе, В. Н. Антоний, архиепископ Зихии (30-50-е гг. XI в.) / В. Н. Чхаидзе // Восточная Европа в древности и средневековье. Вып. ХХXIII. Роль религии в формировании социокультурных практик и представлений. - М. : ИВИ РАН, 2021. C. 308-311.

12. Чхаидзе, В. Н. Печати Иоанна, митрополита Трапезунда (середина XI в.) / В. Н. Чхаидзе // XIII Международный византийский семинар Хврбш̃vos $\theta \varepsilon \dot{\varepsilon} \mu \alpha \tau \alpha$ : «Империя» и «полис» : материалы науч. конф. - Симферополь : ИТ «АРИАЛ», 2021. - C. 291-296.

13. Чхаидзе, В. Н. К церковной археологии Таманского полуострова : Новые находки византийских печатей / В.Н.Чхаидзе, Д. В. Каштанов // Пятая Кубанская археологическая конференция : материалы конф. - Краснодар : Изд-во КубГУ, 2009. - C. 423-426.

14. Alexeenko, N. Die neuen Funde an Bleisiegen aus Cherson / N. Alexeenko, A. Romančuk, I. Sokolova // Studies in Byzantine Sigillography. - 1995. Vol. 4. - S. 139-151.

15. Feind, R. Verse auf byzantinischen Bleisiegeln. Teil 2 : P- $\Omega$ / R. Feind. - Battenberg : Münzen \& Sammeln, 2013. - $664 \mathrm{~S}$.

16. Laurent, V. Le corpus des sceaux de l'Empire byzantin. T. V, 2 : L'Église / V. Laurent. - Paris : Centre National de la Recherche Scietifique, 1965. - 538 p.

17. Laurent, V. Le corpus des sceaux de l'Empire byzantin. T. V, 3 : L'église. Supplément / V. Laurent. - Paris : Centre National de la Recherche Scietifique, $1972 .-343 \mathrm{p}$.

18. Nesbitt, J. Catalogue of Byzantine Seals at Dumbarton Oaks and in the Fogg Museum of Art. Vol. 1. Italy, North of the Balkans, North of the Black Sea / J. Nesbitt, N. Oikonomides. - Washington : Dumbarton Oaks Research Library and Collections, 1991. -253 p.

19. Stepanova, E. New Finds from Sudak / E. Stepanova // Studies in Byzantine Sigillography. 2003. - Vol. 8. - P. 123-130.

20. Wassiliou-Seibt, A.-K. Corpus der byzantinischen Siegel mit metrischen Legenden. T. 2. Einleitung, Siegellegenden von Ny bis inclusive Sphragis /A.-K. Wassiliou-Seibt.-Wien: Verlag derÖsterreichische Akademie der Wissenschaften, 2016. - $767 \mathrm{~S}$.

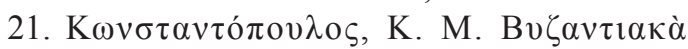

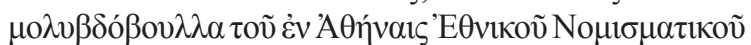

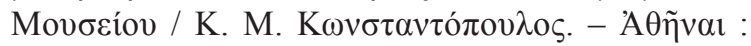
[s. n.], 1917. $-433 \sigma$.

\section{REFERENCES}

1. Alekseenko N.A. Molivdovuly bosporskikh episkopov iz Khersona [Lead Seals of Bosporus Bishops from Kherson]. Problemy religiy stran chernomorsko- 
sredizemnomorskogo regiona [Problems of Religions of the Countries of the Black Sea-Mediterranean Region]. Sevastopol, Krakov, Natsionalnyy zapovednik «Khersones Tavricheskiy», 2001, vol. 2, pp. 131-138.

2. Alekseenko N.A. Tserkovnaya sfragistika: Sacrum et Profanum Konstantinopolskogo patriarkhata [Ecclesiastical Sphragistics: Sacred and Profane of the Patriarchate of Constantinople]. Sacrum et Profanum. Vyp. 4. Religiya $v$ zhizni cheloveka i obshchestva [Sacrum et Profanum. Iss. 4. Religion in the Life of a Person and Society]. Sevastopol, Natsionalnyy zapovednik «Khersones Tavricheskiy», 2009, pp. 25-29.

3. Alekseenko N.A. Pamyatniki arkheologii v ryadu istochnikov po populyarizatsii i razvitiyu sovremennogo turizma: Neskolko novykh molivdovulov bolgarskogo proiskhozhdeniya [Archaeological Monuments in a Number of Sources for the Popularization and Development of Modern Tourism: Several New Molybdoboulla of Bulgarian Origin]. Ottuka zapochva Balgariya. Materiali ot vtorata natsionalna konferentsiya po istoriya, arheologiya i kulturen turizm «Patuvane kam Balgariya» [This is Where Bulgaria Begins. Materials of the Second Annual Conference on History, Archaeology and Cultural Tourism "Journey to Bulgaria"]. Shumen, Universitetsko izdatelstvo «Episkop Konstantin Preslavski», 2011, pp. 352-359.

4. Alekseenko N.A. «Tebya, khranitelya moey dushi i moikh pisaniy, vyrezyvayu na moey pechati...» ["I Carve You, Keeper of My Soul and My Writings, on My Seal..."]. Vestnik Volgogradskogo gosudarstvennogo universiteta. Seriya 4. Istoriya. Regionovedenie. Mezhdunarodnye otnosheniya [Science Journal of Volgograd State University. History. Area Studies. International Relations], 2015, no. 3 (33), pp. 19-29. DOI: http://dx.doi.org/10.15688/jvolsu4.2015.3.2.

5. Alekseenko N.A. Mezhtserkovnye svyazi vizantiyskoy Tavriki: traditsii i novatsii (nakhodki vizantiyskikh molivdovulov v Khersone i ego okruge) [InterChurch Relations of Byzantine Taurica: Traditions and Innovations (Finds of Byzantine Molybdoboulla in Kherson and Its District)]. Bosporskie issledovaniya [Bosporos Studies]. Simferopol, Kerch, Bosporskie issledovaniya, 2019, iss. 38. pp. 225-241.

6. Alekseenko N.A., Samoylenko Yu.N. Molivdovuly deyateley tserkvi iz khersonskogo arkhiva: novye nakhodki [Seals of the Church Leaders from the Kherson Archive: New Findings]. Numizmatichni, sfragistichni i epigrafski prinosi kam istoriyata na Chernomorskoto krayberezhie [Numismatic, Sphragistic and Epigraphic Contributions to the History of the Black Sea Coast]. Varna, Knigoizdatelstvo ZOGRAF Publ., 2008, pp. 91-99. (Acta Musei Variaensis; 7-2).

7. Likhachev N.P. Molivdovuly grecheskogo Vostoka [Molybdoboulla of the Greek East]. Moscow, Nauka Publ., 1991. 359 p. (Nauchnoe nasledstvo [Scientific Heritage]; vol. 19).
8. Chkhaidze V.N. Vizantiyskie pechati iz Tamani [Byzantine Lead Seals from Taman]. Moscow, Institut arkheologii RAN, 2015. 202 p.

9. Chkhaidze V.N. Pechati Ioanna, arkhiepiskopa Gotii (X-XI vv.) [Seals of John, Archbishop of Gothia $\left(10^{\text {th }}-11^{\text {th }} \mathrm{CC}\right.$. $)$ ]. Rossiyskaya arkheologiya [Russian Archaeology], 2016, no. 2, pp. 169-174.

10. Chkhaidze V.N. Palomnicheskaya ampulaevlogiya s Tamanskogo gorodishcha [Pilgrimage Ampoule-Eulogy from the Taman Settlement]. Mir Pravoslaviya [World of Orthodoxy]. Volgograd, Izd-vo VolGU, 2019, iss. 10, pp. 266-271.

11. Chkhaidze V.N. Antoniy, arkhiepiskop Zikhii (30-50-e gg. XI v.) [Antony, Archbishop of Zichia (The 1030s-1050s)]. Vostochnaya Evropa $v$ drevnosti i srednevekove. Vyp. XXXIII. Rol religii v formirovanii sotsiokulturnykh praktik i predstavleniy [Eastern Europe in Antiquity and the Middle Ages. Iss. 33. The Role of Religion in the Formation of Socio-Cultural Practices and Ideas]. Moscow, IVI RAN, 2021, pp. 308-311.

12. Chkhaidze V.N. Pechati Ioanna, mitropolita Trapezunda (seredina XI v.) [Seals of John, the Metropolitan of Trebizond (Mid-11 $1^{\text {th }}$ Century)]. XIII Mezhdunarodnyy vizantiyskiy seminar Chersōnos themata: «Imperiya» $i$ "polis»: materialy nauch. konf. [Proceedings of the $13^{\text {th }}$ International Scientific Conference Byzantine Seminar Chersonos themata: "Empire" and "Polis"]. Simferopol, IT "ARIAL" Publ., 2021, pp. 291-296.

13. Chkhaidze V.N., Kashtanov D.V. K tserkovnoy arkheologii Tamanskogo poluostrova: novye nakhodki vizantiyskikh pechatey [On the Church Archaeology of the Taman Peninsula: New Finds of Byzantine Lead Seals]. Pyataya Kubanskaya arkheologicheskaya konferentsiya: materialy konf. [Proceedings of the Fifth Kuban Archaeological Conference]. Krasnodar, Izd-vo KubGU, 2009, pp. 423-426.

14. Alexeenko N., Romančuk A., Sokolova I. Die neuen Funde an Bleisiegen aus Cherson. Studies in Byzantine Sigillography, 1995, vol. 4, S. 139-151.

15. Feind R. Verse auf byzantinischen Bleisiegeln. Teil. 2: R-Ō. Battenberg, Münzen \& Sammeln, 2013. $664 \mathrm{~S}$.

16. Laurent V. Le corpus des sceaux de l'Empire byzantin. T. 5, 2: L'Église. Paris, Centre National de la Recherche Scietifique, 1965. 538 p.

17. Laurent V. Le corpus des sceaux de l'Empire byzantin. T. 5, 3: L'église. Supplément. Paris, Centre National de la Recherche Scietifique, 1972. 343 p.

18. Nesbitt J., Oikonomides N. Catalogue of Byzantine Seals at Dumbarton Oaks and in the Fogg Museum of Art. Vol. 1. Italy, North of the Balkans, North of the Black Sea. Washington, Dumbarton Oaks Research Library and Collections, 1991. 253 p.

19. Stepanova E. New Finds from Sudak. Studies in Byzantine Sigillography, 2003, vol. 8, pp. 123-130. 


\section{ВИЗАНТИЙСКАЯ СФРАГИСТИКА}

20. Wassiliou-Seibt A.-K. Corpus der byzantinischen Siegel mit metrischen Legenden. T. 2. Einleitung, Siegellegenden von Ny bis inclusive Sphragis. Wien, Verlag der Österreichische Akademie der Wissenschaften, 2016. $767 \mathrm{~S}$.
21. Kōnstantopoulos K.M. Byzantiaka molybdoboulla tou en Athēnais Ethnikou Nomismatikou Mouseiou [Byzantine Lead Seals from the Numismatic Museum of Athens]. Athens, s. n., 1917. 433 p.

\section{Information About the Author}

Viktor N. Chkhaidze, Candidate of Sciences (History), Head of the Centre for Byzantine-Caucasian Studies, Institute of Oriental Studies of the Russian Academy of Sciences, Rozhdestvenka St, 12, 107031 Moscow, Russian Federation, chkhaidze@yandex.ru, https://orcid.org/0000-0003-0806-6218

\section{Информация об авторе}

Виктор Николаевич Чхаидзе, кандидат исторических наук, заведующий Центром византийско-кавказских исследований, Институт востоковедения РАН, ул. Рождественка, 12, 107031 г. Москва, Российская Федерация, chkhaidze@yandex.ru, https://orcid.org/0000-0003-0806-6218 